\title{
Studi Perbandingan Sistem Pendidikan Dasar di Indonesia dan Finlandia
}

\author{
Elise Muryanti ${ }^{1 凶}$, Yuli Herman $^{2}$ \\ Pendidikan Guru Pendidikan Anak Usia Dini, Universitas Negeri Padang, Indonesia(1) \\ Pendidikan Bahasa Inggris, Universitas Mahaputra Muhammad Yamin, Indonesia(2) \\ DOI: $\underline{10.31004 / o b s e s i . v 6 i 3.1696}$
}

\begin{abstract}
Abstrak
Indonesia berupaya memajukan pendidikan melalui program merdeka belajar yang memberikan kebebasan bagi guru dalam berinovasi, kreatif, dan belajar mandiri dalam melakukan penyelenggaraan pendidikan. Konsep merdeka belajar mengadopsi sistem pendidikan dari negara Finlandia yaitu memberikan kebebasan guru untuk berinovasi, mandiri, aktif, kreatif, dan inovatif dalam aktivitas pembelajaran. Penelitian ini menggunakan studi deskriptif komparatif yaitu membandingkan sistem pendidikan dasar di Indonesia dan Finlandia. Sumber data adalah data primer yang diperoleh melalui observasi pada anak kelas awal berusia 7-8 tahun. Sedangkan data sekunder menggunakan kajian literatur dan analisis video pelaksanaan kegiatan sistem pendidikan dari dua negara. Kemudian data dianalisis menggunakan metode deskriptif analisis. Berdasarkan hasil yang diperoleh Finlandia memiliki dukungan yang luar biasa dari pemerintah berupa adanya penyediaan fasilitas sekolah, kualifikasi guru, kesetaraan dan pemerataan pendidikan dibandingkan Indonesia. Disisi lain Indonesia dan Finlandia memiliki keunikan sistem pendidikan masing-masing dan telah menerapkan sistem pendidikan yang terbaik sesuai dengan kondisi dan kemampuan masing-masing negara.
\end{abstract}

Kata Kunci: sistem pendidikan; pendidikan dasar; indonesia; finlandia.

\begin{abstract}
Indonesia seeks to advance education through an independent learning program that provides freedom for teachers to innovate, be creative, and learn in conducting education. The concept of independent learning adopts the education system of Finland, which gives teachers the freedom to innovate, be independent, active, creative, and innovative in learning activities. This study uses a comparative descriptive study that compares the basic education systems in Indonesia and Finland. The Source of data is primary data obtained through observation of early grade children aged 7-8 years. While secondary data uses literature review and video analysis of the implementation of education system activities from two countries. Then the data were analyzed using the descriptive analysis method. Based on the results obtained, Finland has extraordinary support from the government in the form of providing school facilities, teacher qualifications, equality, and equity in education compared to Indonesia. So, Indonesia and Finland have their unique education systems and have implemented the best education system according to the conditions and capabilities of each country.
\end{abstract}

Keywords: education system; basic education; indonesia; finland.

Copyright (c) 2021 Elise Muryanti

Corresponding author : 
Email Address : elise@fip.unp.ac.id (Padang, Sumatera Barat, Indonesia)

Received 30 March 2021, Accepted 12 August 2021, Published 12 August 2021

\section{PENDAHULUAN}

Pendidikan di Finlandia pada tahun 1980 tidak lebih baik dari pada pendidikan di Indonesia, namun dalam 30 tahun terakhir Finlandia mengalami kemajuan yang sangat pesat di bidang pendidikan (Adha, 2019: 147). Ada beberapa hal yang membuat Finlandia maju dalam pengembangan pendidikan, terutama pada jenjang sekolah dasar diantaranya: adanya dukungan pemerintah dalam memfasilitasi sarana dan prasarana pendidikan, serta penyediaan pendidikan gratis untuk semua guru. Rata-rata pendidikan guru yang mengajar di sekolah dasar adalah lulusan program magister pendidikan dan bahkan lulusan doktor pendidikan (Adha, 2019).

Sistem pendidikan Finlandia berlandaskan pada kesetaraan, kerjasama, tanggung jawab, dan berbudaya sehingga dapat memberikan hasil yang sangat efektif dalam mengembangkan pendidikan yang baik (Putra, 2015). Finlandia sukses memberikan dukungan dan fasilitas pendidikan untuk semua warganya dan menjadi negara yang memberikan kesetaraan dalam bidang pendidikan. Sistem pendidikan di Finlandia memperoleh pencapaian yang tinggi dalam pemerataan pendidikan (education for all) dan hasil literasi berada pada pencapaian yang luar biasa (O.E.C.D. 2016; Ustun and Eryilmaz 2018; dan Halinen 2018). Salah satu bentuk dukungan yang diberikan yaitu sekolah di Finlandia diberikan subsidi sejak pendidikan dasar sampai perguruan tinggi, sehingga setiap warga negara tanpa terkecuali dapat menikmati pendidikan gratis di sekolah Finlandia.

Sedangkan kebijakan sistem pendidikan di Indonesia dapat dilihat pada peraturan perundang-undangan yaitu undang-undang (UU) tahun 1945 dan UU pemerintah dalam kebijakan pendidikan UU Sistem Pendidikan Nasional no 20 tahun 2003. Pada UU tahun 1945 pasal 31 setelah diamandemen yaitu: (1) Setiap warga negara berhak mendapat pendidikan; (2) Setiap warga negara wajib mengikuti pendidikan dasar dan pemerintah wajib rnembiayainya; (3) Pemerintah mengusahakan dan menyelenggarakan satu sistem pendidikan nasional, yang meningkatkan keimanan dan ketakwaan serta akhlak mulia dalam rangka mencerdaskan kehidupan bangsa, yang diatur dengan undang-undang; (4) Negara memprioritaskan anggaran pendidikan sekurang kurangnya dua puluh persen dari anggaran pendapatan dan belanja negara serta dari anggaran pendapatan dan belanja daerah untuk memenuhi kebutuhan penyelenggaraan pendidikan nasional; dan (5) Pemerintah memajukan ilmu pengetahuan dan teknologi dengan menjunjung tinggi nilai-nilai agama dan persatuan bangsa untuk kemajuan peradaban serta kesejahteraan umat.

Dari uraian pasal diatas dapat dipahami bahwa pemerintah Indonesia menjamin pelaksanaan pendidikan di Indonesia. Peraturan perundang-undangan negara Republik Indonesia secara jelas menyatakan bahwa negara memprioritaskan pada anggaran dan pelaksanaan pendidikan. Namun untuk kelancaran pelaksanaanya di lapangan, negara perlu melakukan pengawasan dan evaluasi yang transparan berkaitan sejauh mana pelaksanaan program pendidikan di daerah dapat terlaksana dengan baik.

Berdasarkan data statistik tahun 2019 masih terlihat ketidakseimbangan pendidikan di wilayah terpencil Nusa Tenggara Timur. Jika pasal 31 dapat berjalan dengan baik, maka angka putus sekolah di NTT akan dapat diminimalisir sehingga pemerataan pendidikan dapat berjalan sesuai yang dicita-citakan. Namun pada kenyataannya, perjalanan sejarah sistem pendidikan di Indonesia sejak tahun 1947 telah terhitung 10 kali terjadi pergantian kurikulum pendidikan nasional. Adapun tujuan pergantian tersebut untuk meningkatkan kualitas pendidikan dan tentunya agar dapat menemukan formula yang tepat bagi dunia pendidikan di Indonesia sesuai dengan karakter anak bangsa (Adha, 2019: 147).

Sedangkan perkembangan sistem pendidikan di Finlandia menempati posisi sistem pendidikan terbaik di dunia. Dibalik kesuksesan perkembangan pendidikan di Finlandia ternyata menganut paham ajaran yang sama dari Ki Hadjar Dewantara yaitu lebih mengutamakan proses, kegiatan pendidikan berpusat pada anak, dan mengutamakan 
keseimbangan antara rasa, cipta, dan karsa dalam diri anak (Ratri, Supriyanto, and Sobri, 2020: 36). Lain halnya di Indonesia dalam penerapan konsep dasar pendidikan Ki Hajar Dewantara justru tidak berjalan dengan baik. Hal ini dikarenakan kurang adanya keselarasan antara lingkungan sekolah, keluarga, dan masyarakat atau disebut dengan Tripusat Pendidikan.

Sistem pendidikan di Indonesia telah melaksanakan kurikulum 2013 yang bereformasi dalam mempertahankan karakteristik peserta didik (Baswedan, 2014). Namun dalam pelaksanaannya, kurikulum 2013 membutuhkan keseriusan pemerintah dalam memenuhi sumber daya manusia sesuai dengan bidang atau kompetensi yang dibutuhkan. Kemudian baru-baru ini Menteri Pendidikan Indonesia, Nadiem Makariem, memberikan terobosan baru dalam mengatasi kualitas pendidikan dan pembelajaran di Indonesia yaitu melalui program merdeka belajar (Prameswari, 2020).

Konsep merdeka belajar merupakan kemerdekaan berpikir dan guru menjadi bagian terpenting dalam keberhasilan program ini. Guru dan murid merupakan bagian dari subjek dalam sistem pembelajaran. Maknanya guru bukan sumber kebenaran mutlak bagi siswa, namun guru dan siswa saling berkolaborasi mencari kebenaran dan guru berperan menggali daya nalar siswa agar dapat kritis dalam melihat pengetahuan disekitarnya (Yamin \& Syahrir, 2020: 127). Pelaksanaan kegiatan belajar tidak terfokus dilaksanakan di dalam kelas, melainkan dapat dilaksanakan di luar kelas. Selain itu, kegiatan belajar tidak hanya terfokus mendengarkan penjelasan guru, namun peserta didik dibentuk memiliki karakter mandiri, berani, berkompetensi, dan cerdik dalam bergaul serta tidak mengandalkan sistem perangkingan kelas (Yusuf and Arfiansyah, 2021: 128).

Dalam konsep merdeka belajar, guru berperan sebagai fasilitator dan penggerak, serta diberikan kebebasan berinovasi, kreatif, dan belajar mandiri dalam melakukan penyelenggaraan pendidikan (Yusuf \& Arfiansyah, 2021: 129). Dengan demikian dapat dimaknai bahwa merdeka belajar menekankan pada aspek keleluasaan, kebebasan, dan kemerdekaan bagi lembaga pendidikan dalam mengeksplorasi kompetensi siswa. Guru memiliki kesempatan menjadi bagian terpenting dalam pendidikan, karena guru berperan sebagai fasilitator dalam pengembangan karakter siswa.

Sedangkan kurikulum pendidikan dasar di Finlandia menekankan keterampilan anak pada aktivitas bermain dan belajar, serta pelaksanaan pembelajaran mengutamakan proses yang dilakukan secara bertahap (Kasihadi, 2016). Pendidikan di Finlandia menganut nilai pendidikan liberal yaitu kesetaraan, kebebasan, dan rasionalitas mendukung program pendidikan termasuk penyelenggaraan pendidikan guru (Setiawan, 2019: 30). Dalam hal ini pemerintah Finlandia sangat memperhatikan mutu pendidikan yang berkaitan dengan kurikulum, fasilitas, dan kualifikasi pendidikan guru. Sistem pendidikan di Finlandia lebih menekankan "learning community" yaitu adanya kolaborasi antara masyarakat, guru dan siswa yang berperan dalam proses pendidikan (Daud, 2019: 28).

Konsep learning community yang dianut Finlandia memiliki kesamaan dengan konsep pendidikan Ki Hadjar Dewantara "tripusat pendidikan" yang terdiri dari: pendidikan di lingkungan keluarga, di lingkungan sekolah, dan lingkungan masyarakat (Sugiarta, dkk., 2019). Dalam hal ini tripusat pendidikan tidak dapat dipisahkan satu sama lainnya sama halnya dengan learning community. Hal ini dikarenakan keseluruhan aspek yang terdapat di dalam learning community dan tripusat pendidikan memerlukan kerjasama agar dapat memperoleh hasil yang baik serta tujuan pendidikan dapat terlaksana dengan maksimal. Hal ini terbukti dengan kemajuan Finlandia dalam menerapkan sistem pendidikannya dan menjadi sistem pendidikan terbaik di dunia.

Pendidikan merupakan sektor vital dalam suatu negara. Perkembangan suatu negara ditentukan sejauhmana sumber daya manusianya memiliki pendidikan yang baik. Hal ini menjadi orientasi dan perhatian khusus bagi pemerintah di Finlandia dengan melakukan seleksi tenaga pendidik secara ketat. Guru disetiap lembaga pendidikan di Finlandia berasal dari kualifikasi terbaik yang memiliki gelas magister (S2) sesuai dengan bidangnya dan termasuk $10 \%$ dari lulusan terbaik. Selain itu guru mempunyai hak yang sama untuk 
disekolahkan namun guru diwajibkan mengajar walaupun sedang berstatus melakukan studi lanjutan (Faradiba and Lumbantobing, 2020: 68-69).

Berbeda di Indonesia, yang mana tenaga pendidik yang berkarir tidak pada bidangnya atau bahkan kualifikasi pendidikan tidak sesuai dengan yang dipersyaratkan. Setiawan (2019: 27) menyebutkan beberapa penyebab rendahnya kualifikasi yang dimiliki guru di Indonesia diantaranya: kualifikasi guru yang tidak sesuai dengan bidang yang diajar, ketidaksesuaian bidang disiplin ilmu yang diajarkan sehingga berdampak pada penguasaan materi pembelajaran, dan program keprofesian guru masih belum menjangkau semua kalangan pendidik.

Berdasarkan hasil Assessment Internasional dalam literasi, Finlandia tercatat secara konsisten berada di antara pencapaian teratas di PISA sebagai hasil dari skor melek huruf dan negara ini juga sangat tinggi disetiap domain serta pencapaiannya yang luar biasa dalam hal pemerataan pendidikan (Ustun \& Eryilmaz, 2018). Sistem pendidikan Finlandia telah menarik perhatian luar biasa dari banyak negara di seluruh dunia, karena telah menjadi salah satu yang berkinerja terbaik sejak administrasi PISA pertama pada tahun 2000.

Dalam perkembangan dan memajukan sumber daya manusia perlu mempelajari kebijakan-kebijakan dan sistem pendidikan dari berbagai negara. Dengan melakukan studi komparatif antara sistem pendidikan Indonesia dan negara maju yang dikenal terbaik dalam praktik pengembangan pendidikannya, seperti sistem pendidikan negara Finlandia dapat menjadi pengetahuan baru bagi pengembangan dunia pendidikan. Adapun tujuan dari pengkajian dan pembahasan sistem pendidikan Indonesia dan Finlandia terutama pada bidang pendidikan dasar adalah untuk membandingkan sisi terbaik dari masing-masing pendidikan dari dua negara yaitu Finlandia dan Indonesia.

Berdasarkan penjabaran tersebut artikel ini bertujuan untuk mengkaji perbandingan sistem pendidikan di negara Finlandia dan Indonesia yang dilihat dari aspek fasilitas, lingkungan belajar, assessment, kualifikasi guru, dan implementasi kurikulum yang digunakan di dua negara. Dengan mempelajari sistem pendidikan di Indonesia dan Finlandia dapat memberikan pengetahuan baru terkait keunikan dan cara terbaik yang dilakukan dua negara dalam membangun pendidikan dan persiapan sumber daya manusia yang berkompeten di masa depan, serta dalam hal penerapan sistem pendidikan yang sesuai dengan kondisi dan kemampuan masing-masing negara.

\section{METODOLOGI}

Penelitian ini merupakan jenis studi deskriptif komparatif yaitu memandingkan antara sistem pendidikan dasar Indonesia dan Finlandia dengan menggunakan pendekatan kualitatif. Pendidikan dasar yang dimaksudkan dalam tulisan ini tertuju pada anak kelas awal yaitu berusia 7-8 tahun. Sumber data yang digunakan menggunakan data primer yang diperoleh melalui observasi pada anak kelas awal berusia 7-8 tahun dan data sekunder diperoleh melalui hasil penelitian terdahulu dan video pelaksanaan kegiatan belajar yang diperoleh di youtube.

Observasi dilakukan ketika studi banding di salah satu sekolah dasar, Joensuu Finland selama 1 bulan. Untuk mempelajari bagaimana sistem pendidikan di kedua negara yaitu Indonesia dan Finlandia, maka dilakukan dengan menggunakan beberapa metode diantaranya: observasi, studi literatur, dan mempelajari sistem pendidikan Finlandia melalui video pelaksanaan kegiatan belajar. Selanjutnya data dianalisis menggunakan metode deskriptif analisis (Gunawan, 2013) menggunakan tiga tahap yaitu reduksi data, display data, dan penarikan kesimpulan sebagaimana digambarkan pada gambar 1. 


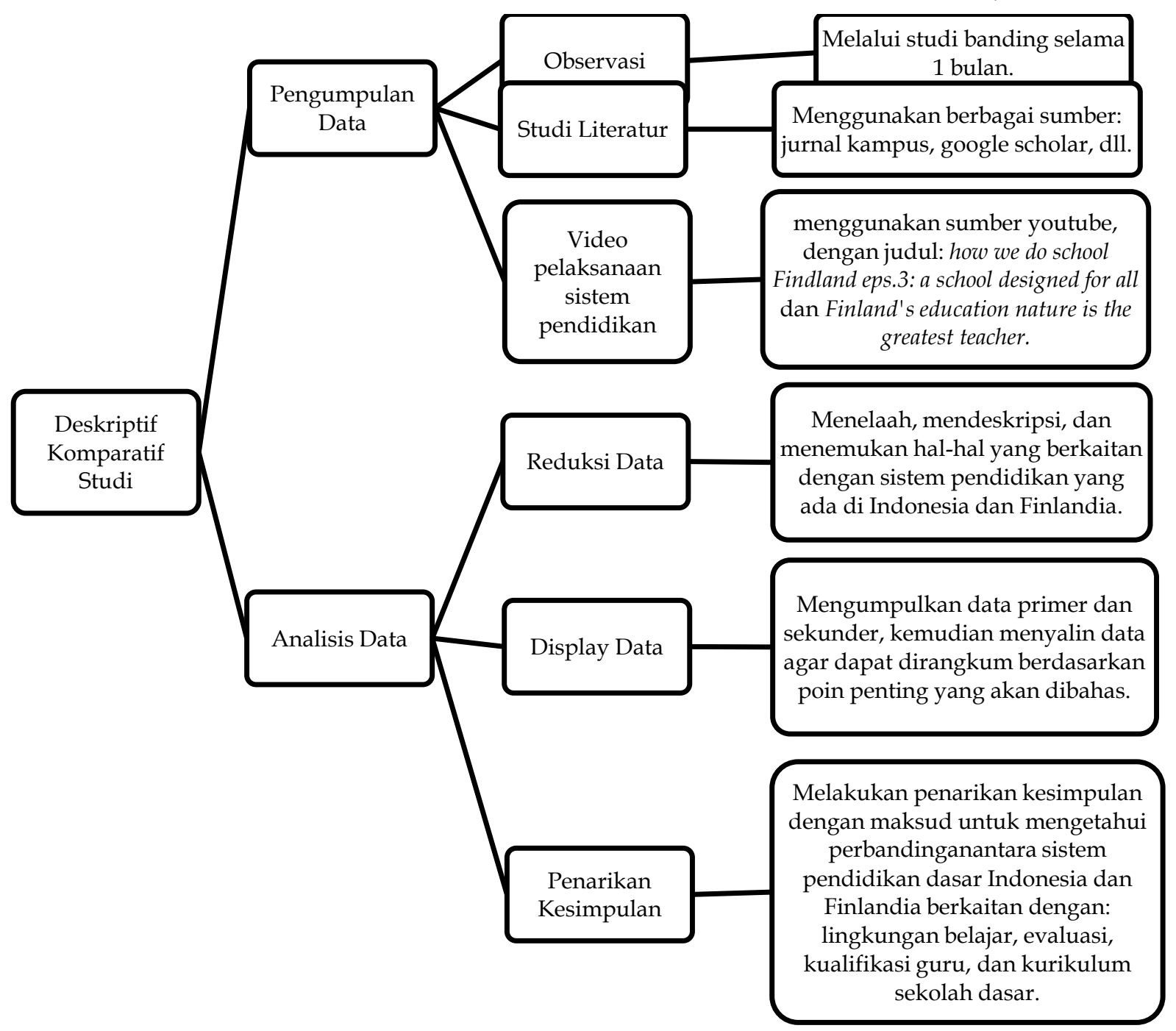

Gambar 1. Desain Penelitian

\section{HASIL DAN PEMBAHASAN}

Berdasarkan observasi sekolah dasar di Joensuu Finlandia, terlihat bahwa Sekolah Dasar di Finlandia mendapatkan dukungan fasilitas yang lengkap. Gedung yang besar dengan fasilitas hall olah raga, lapangan bermain, ruangan untuk belajar musik, ruangan kelas yang dilengkapi dengan alat alat musik, ruang tunggu untuk anak anak duduk diskusi dan bereksplorasi menggunakan tablet serta note book mereka. Dengan fasilitas yang lengkap tentu Finlandia menjadi negara terdepan dalam dunia pendidikan.

Ketika sekolah dasar di Indonesia mendapatkan fasilitas yang sama dengan sekolah di Finlandia tentu akan lebih baik mutu dan kualitas pelaksanaan pembelajaran. Saat sekarang ini sekolah swasta di Indonesia dikategorikan memiliki fasilitas yang lumayan lebih baik dari segi pengelolaan dan pencapaian akademis, dibandingkan sekolah dasar negeri di Indonesia yang dikelola dengan keterbatasan sarana dan prasarana.

Indonesia merupakan negara yang sedang berkembang dan sistem pendidikan dasar masih perlu lebih ditingkatkan. Dukungan pemerintah dalam beberapa masa sudah mulai meningkat dalam pengembangan pendidikan dasar di Indonesia. Dalam undang-undang dasar (UUD) Republik Indonesia 1945 dijelaskan bahwa setiap warga Negara berhak mendapatkan pendidikan. Pada pembukaan UUD 1945 dijelaskan bahwa tujuan pembangunan Indonesia adalah dalam upaya mencerdaskan kehidupan bangsa dan negara menjamin setiap warga negara dalam mendapatkan pendidikan.

Namun pada kenyataannya, pendidikan belum dapat terakses oleh semua warga negara Indonesia. Hal ini ditandai dengan tingginya angka putus sekolah di Indonesia pada 
tahun 1999 dari data statistik sekitar 23,3\%. Angka terbesar berada di Nusa Tenggara Timur dan peringkat usia yang terbesar adalah usia sekolah dasar (Anak Putus Sekolah Info Grafis, 2019). Ini berarti bahwa tidak meratanya pendidikan di Indonesia. Persamaaan dalam pendidikan di Indonesia belum berjalan seperti yang diharapkan dan pemanfaatan dana pendidikan belum berjalan secara menyeluruh. Masalah pendidikan di Indonesia akan dapat diselesaikan dengan meningkatkan dukungan pada penyediaan pendidikan gratis. Bantuan pemerintah dalam bentuk dana BOS (Bantuan operasional Sekolah) perlu ditingkatkan lagi dan di awasi agar bantuan tersebut dapat digunakan untuk meningkatkan kebutuhan fasilitas sekolah.

Pemerintah Finlandia sangat memperhatikan seluruh peserta didik agar dapat memperoleh pendidikan yang bermutu, karena dipandang sebagai aset penting bangsa (Kasihadi, 2016). Sedangkan di Indonesia, sekolah yang bermutu hanya dapat dinikmati oleh anak-anak dari kalangan menengah ke atas. Hal ini dikarenakan sekolah bermutu dikategorikan memiliki biaya pendidikan yang tinggi, sehingga bagi kalangan menengah ke bawah sangat sulit untuk dapat menjangkau pendidikan tersebut (Widodo, 2016). Maka dapat dimaknai untuk mendapatkan pendidikan yang bermutu akan semakin menimbulkan kesenjangan dikalangan masyarakat Indonesia.

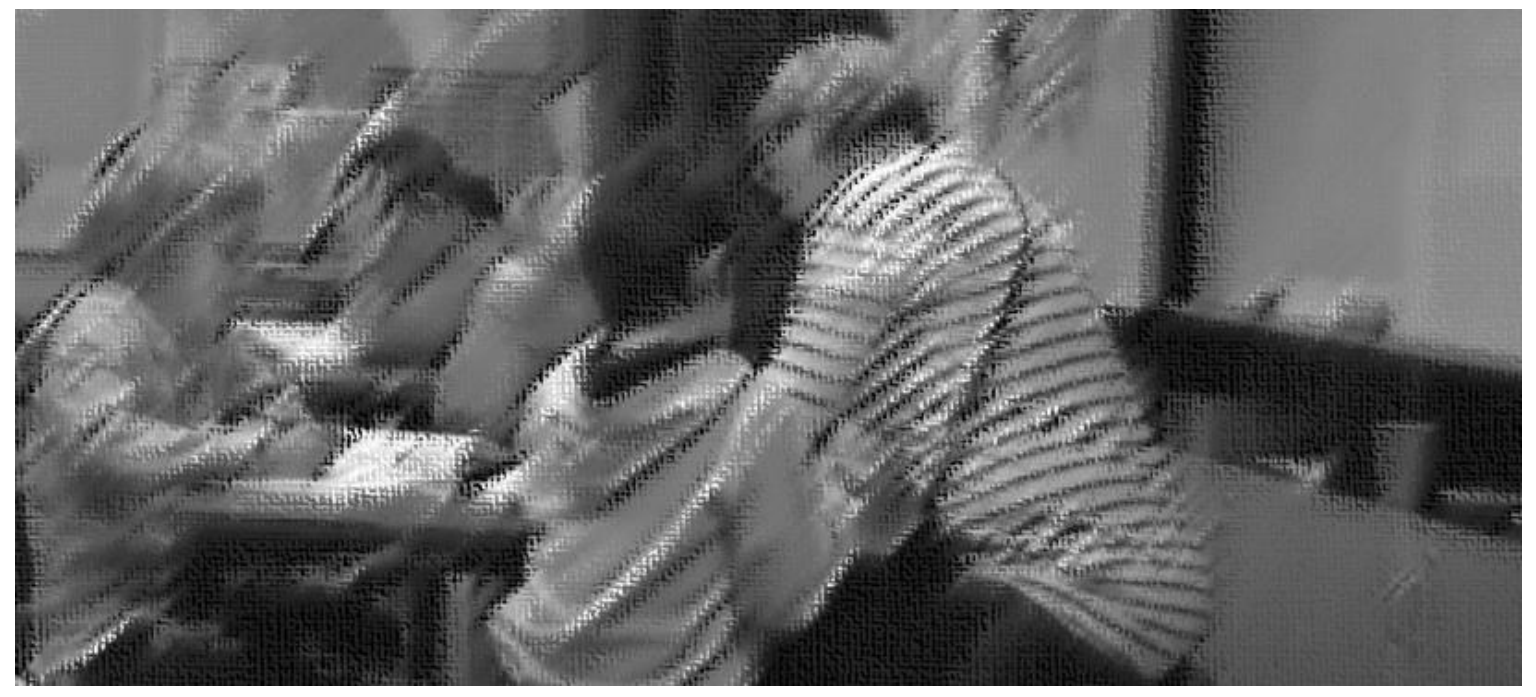

Gambar 2. Pelaksanaan kegiatan belajar di sekolah dasar Finlandia

Sekolah dasar di Helsinki yang diamati pada potongan gambar video di atas menggambarkan pelaksanaan pembelajaran bagi anak kelas awal (usia 7-8 tahun) berlangsung 4 jam per hari atau hanya dibebani \pm 20 jam seminggu. Jam sekolah di Finlandia dikatakan lebih pendek dibandingkan jam belajar di Australia dan termasuk Indonesia. Di Indonesia anak kelas awal yaitu SD kelas 1 melaksanakan kegiatan belajar mulai pukul 08.00 WIB s/d 13.00 WIB. Maka dapat dikalkulasikan, anak kelas awal di Indonesia menghabiskan waktu belajar di Sekolah selama 5 jam per hari dari hari Senin s/d kamis, kecuali Jumat anak lebih cepat pulang.

Di sekolah dasar Finlandia, guru diberikan otoritas dalam menentukan kurikulum sekolah termasuk diberikan kebebasan penuh dalam pemilihan dan pemanfaatan teknologi. Dengan demikian guru di Finlandia dapat mengembangkan kreativitas dan inovasi dalam merancang dan melakukan pembelajaran. Guru di Finlandia memiliki peran utama dalam melaksanakan berbagai bentuk metode, strategi, dan regulasi penerapan kurikulum nasional (Adha, 2019: 151). Maka dapat dimaknai, guru menjadi panutan utama bagi siswa di sekolah dan menjadi sosok yang dihargai di kalangan masyarakat umum. Lain halnya di Indonesia, guru ditetapkan sebagai pelaksana kurikulum. Guru diminta merancang kurilum pembelajaran dalam bentuk perancangan kegiatan harian yang kompleks. Ibarat seperti katak 
di dalam tempurung, guru belum mampu berinovasi secara bebas dalam merancang pembelajaran.

Selanjutnya, anak kelas awal di Finlandia belajar minimal 20 jam per minggu dan seiring dengan pertambahan usia, maka jam pelajaran akan bertambah. Guru juga dapat menentukan kurikulum yang digunakan di ruang kelas. Anak-anak di sekolah dasar Finlandia menjalankan kafe yang dapat memberikan pengalaman bagi anak untuk berdagang dan bekerja di kafe sekolah.

Ada banyak pilihan tempat bermain bagi anak-anak sekolah dasar di Finland, seperti: area untuk bermain skating, pimpong, bola basket, dan lainnya. Sekolah dasar Finlandia tidak diperbolehkan mengambil dana pribadi, untuk makan siang dan buku-buku disubsidi oleh pemerintah sehingga anak mendapatkan makan siang dan buku gratis di sekolah. Dengan demikian, sekolah dapat memberikan layanan yang sama, tidak ada biaya yang dikeluarkan orangtua untuk sekolah anak.

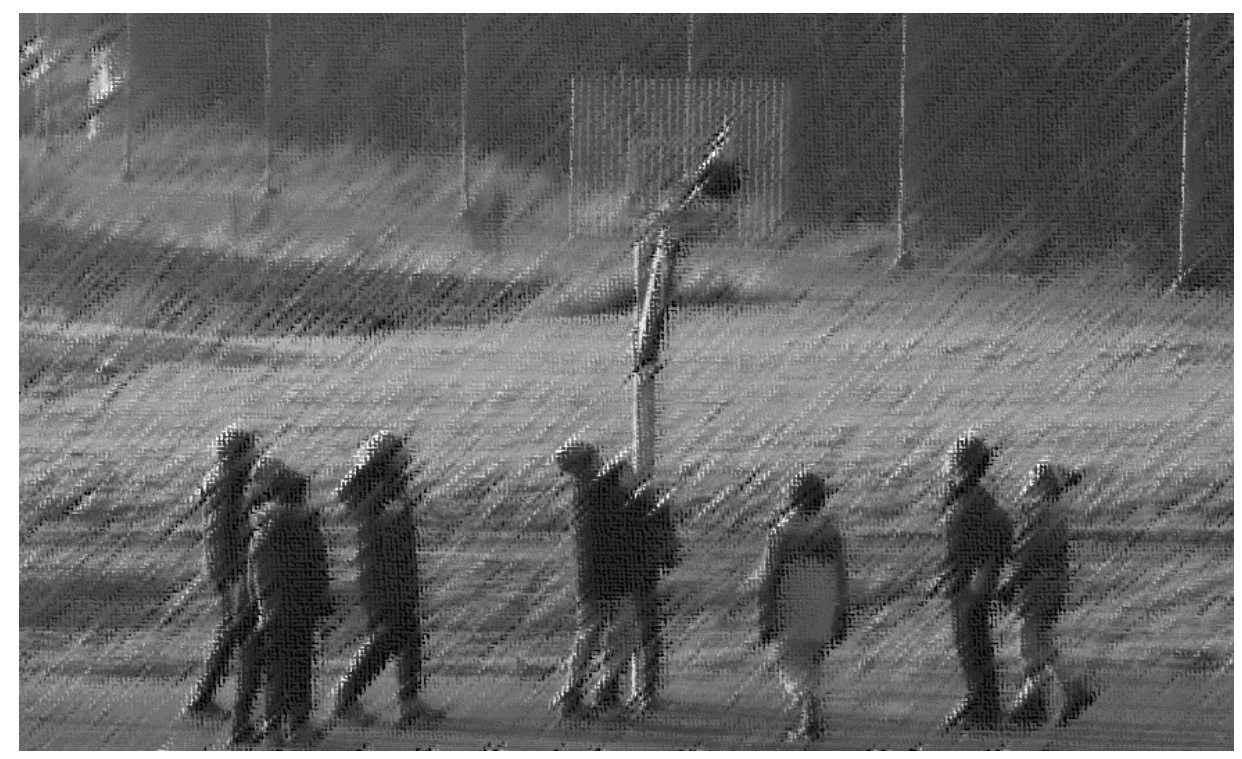

\section{Lingkungan Belajar}

Gambar 3. Area bermain

Sekolah dasar di Finlandia menyediakan lingkungan pembelajaran yang kondusif dan menyenangkan. Guru dan anak di Finlandia didorong untuk berinovasi dan kreatif di dalam pembelajaran. Pembelajaran tidak hanya dilakukan dalam ruangan, namun juga dapat dilakukan dimana saja termasuk di kebun sekolah, hutan dekat sekolah untuk mempelajari pelajaran biologi habitat komunitas tanaman dan hewan yang ada di hutan. Sekali-sekali anak belajar dengan ikut field trip sesuai yang diprogramkan oleh guru dan orang tua anak.

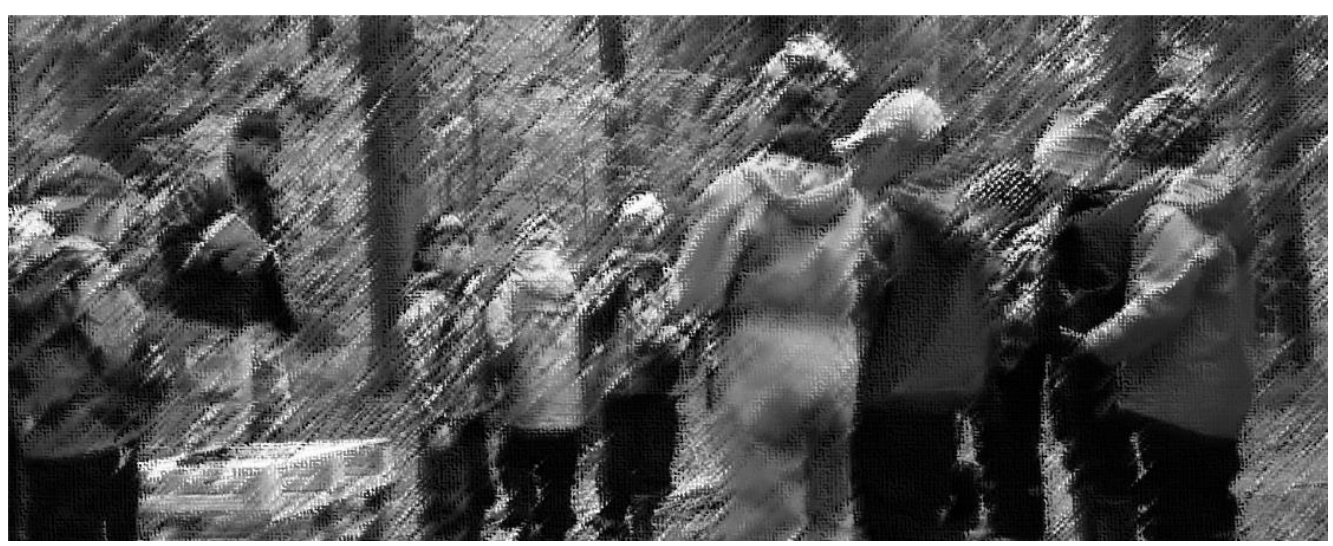

Gambar 4. Kegiatan pembelajaran di luar kelas 
Sekolah Dasar di Finlandia mendukung pada pendidikan inklusi dan memfasilitasi anak-anak berkebutuhan khusus untuk belajar bersama dengan anak-anak yang tidak berkebutuhan khusus. Anak-anak berkebutuhan khusus mendapatkan guru pendamping dan belajar sesuai dengan suasana dan media pembelajaran yang diinginkannya. Anak-anak disleksia yang sulit untuk membaca dan menulis belajar dengan mengunakan buku-buku elektronik yang mengeluarkan suara dengan mengunakan program-program yang sudah diatur di IPad yang digunakan sebagai media pembelajaran. Ipad tersebut memberikan penjelasan pada materi pelajaran mereka sehingga sangat membantu anak disleksia dalam memahami konsep, materi yang mereka pelajari dan juga bermanfaat terutama dalam menghadapi ujian nasional.

Di sekolah dasar Finlandia terdapat ruangan bermain sekaligus tempat bagi anak anak dengan dilengkapi sofa-sofa yang empuk dan bean bed yang bisa digunakan anak-anak untuk istirahat, diskusi ataupun belajar dengan mengunakan laptop dan ipad dilakukan anak anak sekolah. Sekolah di Finlandia juga mendukung pada kesejahteraan dan kesehatan anak. Program pemerintah dalam memperhatikan kesejahteraan dan kesehatan terwujud dalam bentuk penyediaan klinik kesehatan ibu dan anak, mulai dari tingkat pendidikan anak usia dini, sekolah dasar dan sekolah lanjutan. Pada sekolah dasar di Joensu ditemukan terdapat 2 anak yang mengidap diabetes dan perlu suntik insulin sekali 4 jam. Di sekolah tersebut menyediakan guru pendamping untuk dapat membantu menginjeksi anak tersebut.

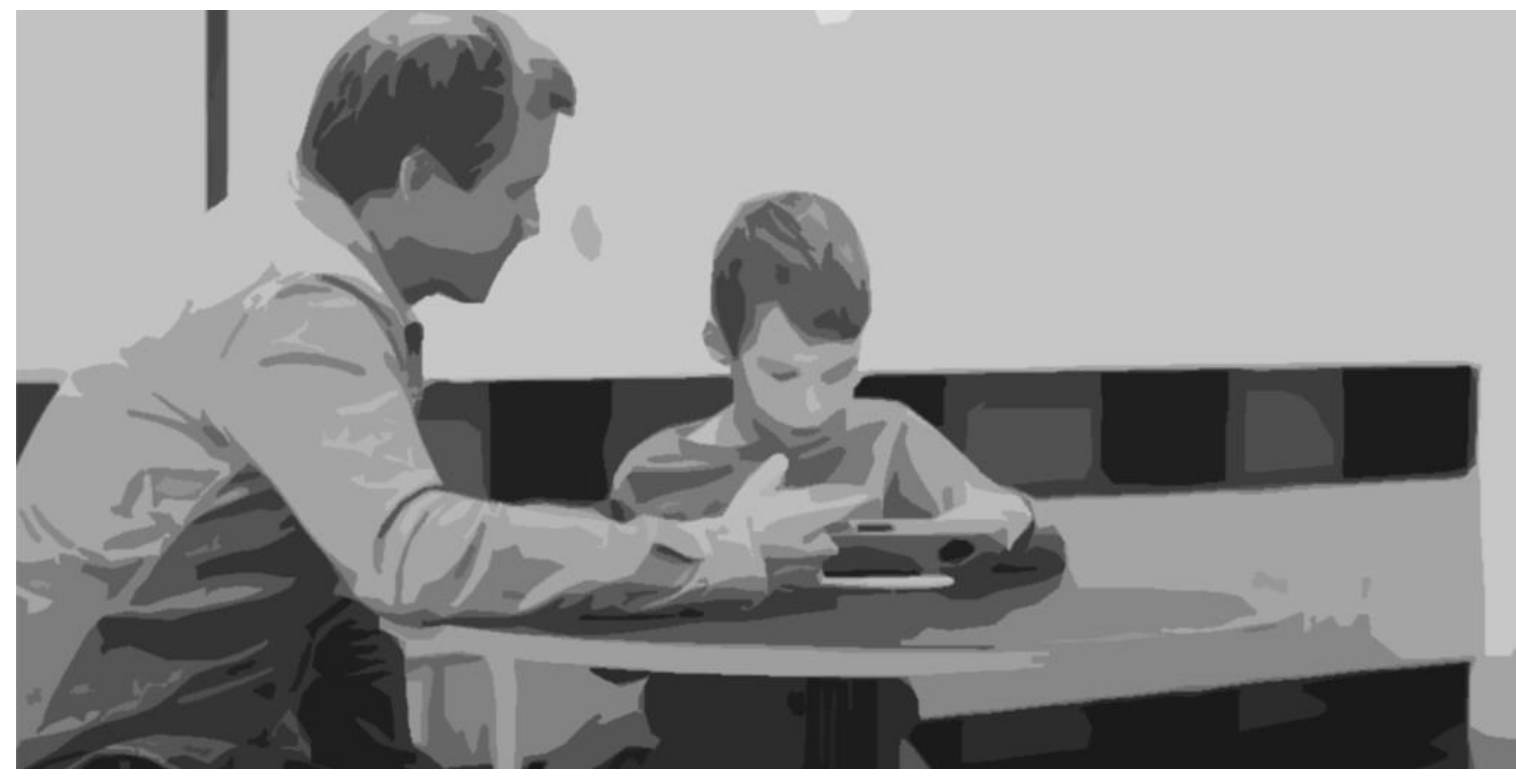

Gambar 5. Penggunaan Ipad pada anak berkebutuhan khusus

\section{Assessment/Evaluasi}

Beberapa praktisi pendidikan di Indonesia menyatakan yang membuat Finlandia berbeda dengan Indonesia adalah tidak adanya ujian. Satu faktor yang membuat Finlandia berhasil adalah anak pada tingkat sekolah dasar di Finland sejak kelas 1 sampai kelas 6 jarang mengikuti ujian (Taylor, 2012; Ashleigh, 2020). Namun hal ini dibantah oleh praktisi pendidikan di Finlandia, menjelaskan bahwa Finlandia memiliki ujian regular yang bertujuan sebagai informasi evaluasi sekolah dan tidak untuk membandingkan sekolah-sekolah di Finlandia (Ashleigh, 2020). Tujuan dari ujian reguler hanya sebagai informasi dan evaluasi dari sekolah tersebut. Anak di Finlandia tidak ada yang tinggal kelas. Finlandia menghargai perbedaan pada setiap anak karena setiap anak memiliki keunikan dalam cara belajar dan memiliki intelengensi yang beragam (multiple intelligence), sehingga anak-anak sekolah dasar tidak ada yang tinggal kelas. 
Anak sekolah dasar di Finlandia dimulai pada usia 7 tahun dan anak sekolah di Finlandia jarang memiliki Pekerjaan rumah. Dilihat pada fenomena sekolah dasar di Indonesia anak-anak sering dipaksakan belajar dengan muatan pelajaran yang banyak dan hafalan-hafalan yang nanti diuji menentukan dalam kenaikan kelas. Beban belajar yang cukup banyak membuat anak sekolah dasar terutama kelas awal 1, 2 dan 3 berkurang waktu bermain mereka. Kurangnya waktu bermain bagi anak usia dibawah 9 tahun akan berdampak pada kelelahan, kejenuhan dan berpengaruh pada perkembangan mereka.

\section{Kualifikasi Guru}

Standard dan kualifikasi guru atau tenaga pendidik di Sekolah Dasar di Finlandia cukup tinggi dimana guru yang mengajar memiliki pendidikan magister. Karir sebagai guru menjadi karir yang diminati di Finlandia. Hal ini bertolak belakang dengan Indonesia dimana menjadi guru adalah pilihan terakhir dan kurang diminati. Sehingga seleksi di Perguruan tinggi keguruan belajar di jurusan ilmu pendidikan haruslah pilihan utama atau dapat dikatakan bahwa menjadi guru harus menjadi pilihan pertama bukan pilihan kedua maupun ketiga.

Untuk menjadi guru, pelamar institusi ilmu keguruan menjalani seleksi yang ketat. Mereka berkompetensi dengan 1000 pelamar lainnya dan pada akhirnya kuota yang dipilih hanya untuk 30 orang. Tentu saja yang terpilih adalah sumber daya guru yang memiliki kelebihan cerdas berwawasan dan cerdas psikologisnya. Guru-guru di Finland terlatih dalam pelaksanaan pembelajaran (Finnish Education Agency, 2020) dan memiliki profesionalisme yang tinggi dalam mengajar. Dengan demikian, semakin meningkat kompetensi yang dimiliki guru dapat membantu peningkatan mutu pendidikan (Utami et al., 2019: 67).

\section{Kurikulum Sekolah Dasar di Finlandia dan Indonesia}

Finish National Core Curriculum (Kurikulum Nasional Finlandia/FNCC) tahun 2014 dibagi menjadi dua bagian. Bagian umum berisikan pentingnya kurikulum lokal, proses kurikulum lokal, misi dan tujuan umum pendidikan dasar, dan penilaian. Pada kurikulum Sekolah Dasar ini bagian yang mencakup konten mata pelajaran dibagi berdasarkan kelas (1 dan 2, serta kelas 3-6). Di dalam FNCC, (2014) menjelaskan anak memperoleh kompetensi dalam bidang pengetahuan individu dan kompetensi yang melintasi batas mata pelajaran (kompetensi transversal dan modul pembelajaran multidisiplin.

Prinsip pendidikan di Finlandia membangun kepercayaan (trust). Pendidikan karakter atau soft skill merupakan hal yang utama yang dibangun di sekolah. Indonesia dalam kurikulum pendidikan 2013 juga meletakkan karakter sebagai mata pelajaran dasar yang dalam praktiknya terintegrasi dengan mata pelajaran lainnya. Dari observasi di Finlandia terlihat bahwa Finlandia sukses dengan pendidikan karakternya terlihat bahwa anak disiplin, kelestarian lingkungan terjaga, mandiri, saling menghargai dan tingkat kejujuran yang tinggi. Sedangkan di Indonesia, program merdeka belajar merupakan perwujudan dari konsep liberalisasi dalam pendidikan. Merdeka dalam arti memberikan kebebasan dalam berkarya dan berinovasi dalam pembelajaran. Guru dalam program merdeka belajar memiliki keleluasaan dalam mengarahkan pembelajaran di kelas. Jika dikaji secara prinsipnya, merdeka belajar sama halnya dengan konsep pendidikan di negara maju seperti Finlandia yang mengutamakan kebebasan dalam berkarya dan berinovasi dalam kegiatan belajar dan pembelajaran. Pembelajaran tidak monoton di dalam ruang kelas namun dapat dilakukan dimanapun, ditempat yang bisa menjadi sumber belajar seperti di lahan pertanian, di perpustakaan, di tepi pantai dan di lapangan olahraga.

Sistem pendidikan di Finlandia memberikan kebijakan lokal pada prioritas pendidikan seperti kurikulum lokal, alokasi subsidi, ukuran kelas, rekrutmen guru, evaluasi guru dan penjaminan mutu (Anon, 2020). Dalam pelaksanaan pendidikan, pihak sekolah di Finlandia melakukan kerjasama dengan berbagai pihak, seperti: otoritas pemerintah nasional dan lokal, organisasi guru, masyarakat, orang tua, anak dan alumni, lembaga penelitian, dan stake 
holder yaitu lembaga pemerintahan dan Industri. Sedangkan di Indonesia, kebijakan merdeka belajar merupakan adopsi dari sistem pendidikan negara maju dan konsep ini sejalan dengan sistem pendidikan di Finlandia. Konsep merdeka belajar mendorong pada pengembangan kompetensi dan membangun keterampilan kerja anak dengan kegiatan praktik di industri kerja.

\section{SIMPULAN}

Sistem pendidikan dasar di Indonesia dan Finlandia memiliki kesamaan kategori usia anak dan guru diberikan kebebasan untuk berkreativitas dan berinovasi dalam mengembangkan pembelajaran. Sedangkan perbedaannya dapat dilihat pada kualifikasi guru, ketersediaan fasilitas, dan kebijakan pemerintah terkait assessment, kesetaraan dan pemerataan mutu pendidikan. Terdapat tiga aspek yang dapat dipelajari dan dikembangkan untuk sistem pendidikan dasar di Indonesia yaitu memfasilitasi kesetaraan dan pemerataan mutu pendidikan di desa dan di kota, menjalankan konsep tripusat pendidikan agar tujuan pendidikan dapat terlaksana dengan maksimal, dan melakukan assesment/evaluasi melalui pelaksanaan ujian sebagai masukan bagi lembaga sekolah dalam meningkatkan pelayanan pendidikan yang tepat dan bermutu.

\section{UCAPAN TERIMA KASIH}

Terima kasih pada SDM Ristekdikti yang telah membiayai program short course Early Childhood education ke Finlandia yang dilakukan selama 1 bulan. Ini bermanfaat dalam menambah keilmuan tentang system Pendidikan antara 2 negara Indonesia dan Finlandia terutama dalam Ilmu Pendidikan Anak Usia Dini.

\section{DAFTAR PUSTAKA}

Adha, M. A., Gordisona, S., Ulfatin, N., \& Supriyanto, A. (2019). Analisis komparasi sistem pendidikan Indonesia dan Finlandia. Jurnal Studi Manajemen Pendidikan, 3(2). https://doi.org/10.29240/jsmp.v3i2.1102

Anak putus sekolah info grafis. (2019). Badan Pusat Statistik. https://ntt.bps.go.id/backend/images/Anak-Putus-Sekolah-ind.jpg

Ashleigh, F. (2020). Not All Finns Think Alike: Varying Views of Assessment in Finland. International Education Studies, 13(1), 1-10.

Baswedan, A. R. (2014). Gawat Darurat Pendidikan di Indonesia pendidikan Indonesia. In The Emergency of Indonesian Education (Vol. 1).

Daud, R. M. (2019). Sistem pendidikan Finlandia suatu alternatif sistem pendidikan Aceh. Indonesia: Fakutas Tarbiyah Dan Keguruan UIN Ar-Raniry, 53(9), 21-36.

Faradiba, \& Lumbantobing, S. S. (2020). Perbandingan penerapan kebijakan pendidikan Indonesia dengan Finlandia. School Education Journal, 10(1), 65-73.

Finnish Education Agency (p. Education in Finland Accessed on https://www.oph.f). (2020).

Gunawan, I. (2013). Metode penelitian kualitatif. Bumi Aksara.

Halinen, I. (2018). The New Educational Curriculum in Finland. Improving the Quality of Childhood in Europe, 7, 75-89.

Kasihadi, R. (2016). Optimalisasi prestasi peserta didik melalui sistem pendidikan yang humanis: suatu perbandingan dengan negara maju. Jurnal Widyatama, 20(2), 145-151.

O.E.C.D. (2016). Excellence and Equity in Education. OECD Publishing, 1.

Prameswari, T. W. (2020). Merdeka belajar: sebuah konsep pembelajaran anak usia dini menuju indonesia emas 2045. Seminar Nasional Penalaran Dan Penelitian Nusantara, $1,76-86$.

Putra, K. . (2015). Resistansi Finlandia terhadap global educational reform. Jurnal Analisis Hubungan Internasional, 4(1), 1393-1421. 
Ratri, D. K., Supriyanto, A., \& Sobri, A. Y. (2020). Pendidikan Indonesia di Masa Depan: Tinjauan Kesesuaian Pendidikan di Finlandia dengan Ki Hadjar Dewantara. Seminar Nasional, 35-40. http://conference.um.ac.id/index.php/apfip/article/view/370

Setiawan, A. Y. (2019). Pendidikan guru berbasis nilai dengan mengkaji penyelenggaraan guru di negara lain dalam mewujudkan visi kurikulum indonesia yang mencerdaskan 2030. Geoarea, 2(1), 25-34.

Sugiarta, I. M., Mardana, I. B. P., Adiarta, A., \& Artanayasa, W. (2019). Filsafat pendidikan Ki Hajar Dewantara (tokoh timur). Jurnal Filsafat Indonesia, 2(3), 124. https:// doi.org/10.23887/jfi.v2i3.22187

Taylor, A. (2012). Why Finland's unorthodox education system is the best in the world. Business Insider. Retrieved from http://www.busine.

Ustun, U., \& Eryilmaz, A. (2018). Analysis of Finnish Education System to Question the Reasons behind Finnish Success in PISA. Online Submission, 2(2), 93-114.

Utami, W. Y. D., Jamaris, M., \& Meilanie, S. M. (2019). Evaluasi Program Pengelolaan Lembaga PAUD di Kabupaten Serang. Jurnal Obsesi : Jurnal Pendidikan Anak Usia Dini, 4(1), 67. https://doi.org/10.31004/obsesi.v4i1.259

Widodo, H. (2016). Potret pendidikan di indonesia dan kesiapannya dalam menghadapi masyarakat ekonomi asia (MEA). Cendekia: Journal of Education and Society, 13(2), 293. https:// doi.org/10.21154/cendekia.v13i2.250

Yamin, M., \& Syahrir, S. (2020). Pembangunan Pendidikan Merdeka Belajar (Telaah Metode Pembelajaran). Jurnal Ilmiah Mandala Education, 6(1), 126-136. https://doi.org/10.36312/jime.v6i1.1121

Yusuf, M., \& Arfiansyah, W. (2021). Konsep "Merdeka Belajar" dalam Pandangan Filsafat Konstruktivisme. AL-MURABBI: Jurnal Studi Kependidikan Dan Keislaman, 7(2), 120 133. https://doi.org/10.53627/jam.v7i2.3996 